\title{
Characterization of Cetyl Trimethylammonium Bromide/Hexanol Reverse Micelles by Experimentally Benchmarked Molecular Dynamics Simulations
}

\author{
Brian Fuglestad, Kushol Gupta, A. Joshua Wand* \& Kim A. Sharp*
}

Johnson Research Foundation and Department of Biochemistry \& Biophysics, University of Pennsylvania, Perelman School of Medicine, Philadelphia, Pennsylvania 19104-6059

* Correspondence to: K. A. Sharp (sharpk@mail.med.upenn.edu) or A. J. Wand (wand@upenn.edu) 


\section{Supplementary Material}

Table S1. Physical properties of the reverse micelle components ${ }^{\mathrm{a}}$

\begin{tabular}{|l|l|l|l|l|}
\hline Molecule & MW $(\mathrm{g} / \mathrm{mole})$ & $\mathrm{V}_{\mathrm{m}}\left(\mathrm{A}^{3}\right)^{\mathrm{b}}$ & $\mathrm{A}_{\mathrm{m}}=\mathrm{V}_{\mathrm{m}} /<1>\left(\AA^{2}\right)$ & $\mathrm{H}_{\text {vap }}\left(\mathrm{Expt}^{\mathrm{b}}\right) \mathrm{kcal} / \mathrm{mole}^{\mathrm{m}}$ \\
\hline Water & 18 & 30 & na & $10.4 \pm 0.1(10.5)$ \\
\hline hexanol & 102 & 208 & 20 & $13.7 \pm 0.2(14.7)$ \\
\hline Pentane & 72 & 195 & na & $5.8 \pm 0.3(6.3)$ \\
\hline CTAB & 284 & 710 & 33 & na \\
\hline Br- & 80 & - & na & na \\
\hline
\end{tabular}

${ }^{\mathrm{a}} \mathrm{MW}=$ molecular weight, $\mathrm{V}_{\mathrm{m}}=$ experimental molar volume, except CTAB, estimated from molecular weight assuming same proportionality as hexanol/pentane. $\mathrm{A}_{\mathrm{m}}=$ effective cross-sectional area. $\mathrm{H}_{\text {vap }}=$ enthalpy of vaporization. na: Not applicable. 'Data from Chemistry WebBook, http://webbook.nist.gov/chemistry/

Table S2. Scattering length densities of micelle components

\begin{tabular}{|l|l|l|}
\hline & X-rays $\left(10^{-6} / \AA^{2}\right)$ & Neutrons $\left(10^{-6} / \AA^{2}\right)$ \\
\hline n-pentane $\left(\mathrm{C}_{5} \mathrm{H}_{12}\right)$ & 6.11 & -0.60 \\
\hline $\mathrm{D}_{2} \mathrm{O}$ & 9.40 & 6.39 \\
\hline $\mathrm{H}_{2} \mathrm{O}$ & 9.47 & -0.56 \\
\hline $\mathrm{C}_{19} \mathrm{H}_{42} \mathrm{~N}$ & 6.48 & -0.30 \\
\hline $\mathrm{C}_{19} \mathrm{D}_{42} \mathrm{~N}$ & 6.48 & 5.86 \\
\hline $\mathrm{Br}$ & 24.68 & 1.73 \\
\hline hexanol $\left(\mathrm{C}_{6} \mathrm{H}_{14} \mathrm{O}\right)$ & 7.88 & -3.21 \\
\hline
\end{tabular}


Table S3. Analysis of scattering data

\begin{tabular}{|l|c|c|c|c|c|c|c|}
\hline & $\mathrm{R}_{\mathrm{g}}(\AA)$ & $\begin{array}{c}\mathrm{D}_{\max } \\
(\AA)\end{array}$ & Fitting Model & $\mathrm{R}_{\text {core }}(\AA)$ & $\begin{array}{c}\mathrm{R}_{\text {shell }}(\AA) \\
(\mathrm{Br})\end{array}$ & $\begin{array}{c}\mathrm{R}_{\text {shell }}(\AA) \\
(\mathrm{CTAB})\end{array}$ & $\chi^{2}$ \\
\hline SAXS & $29.3 \pm 0.08$ & 78.0 & Core-Shell-Shell & $18.9 \pm 0.4$ & $1.88^{\mathrm{b}}$ & $29.5 \pm 0.3$ & 2.86 \\
\hline $\begin{array}{l}\text { SANS }\left(\mathrm{D}_{2} \mathrm{O}\right. \\
\text { Core })\end{array}$ & $20.8 \pm 0.09$ & 57.5 & Sphere & $20.0 \pm 0.3$ & N.A. & N.A. & 0.79 \\
\hline $\begin{array}{l}\text { SANS } \\
\text { (Deuterated } \\
\text { CTAB) }\end{array}$ & $36.3 \pm 0.07$ & 96.9 & Core-Shell-Shell & $12.4 \pm 0.7$ & $1.88^{\mathrm{b}}$ & $31.8 \pm 0.9$ & 2.95 \\
\hline
\end{tabular}

${ }^{\mathrm{a}}$ Model schematics are illustrated in supplementary Figure S1. ${ }^{b}$ Fixed. 


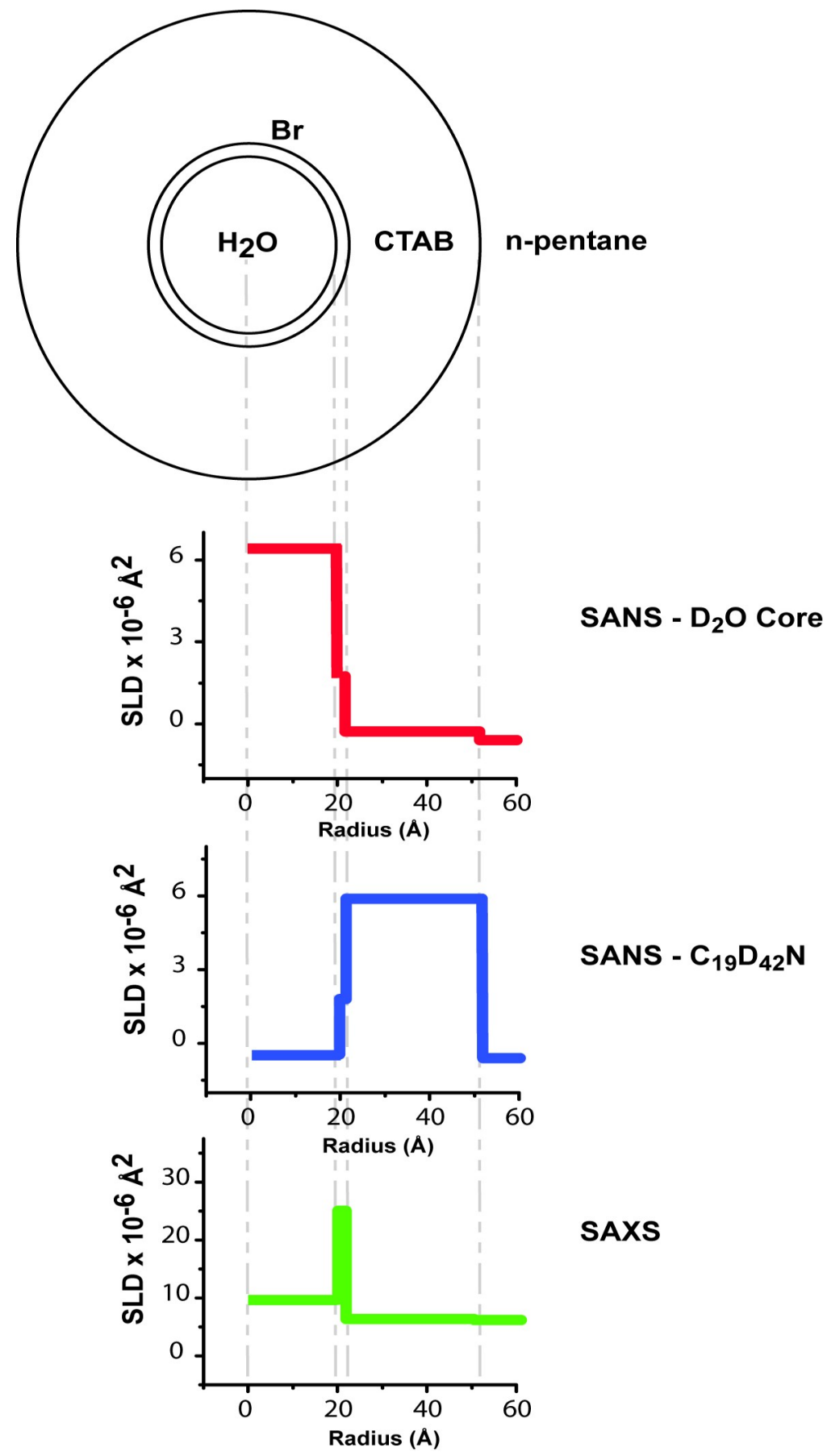

Figure S1. Scattering models used for fitting to data in Figure 1. See Table S2. 

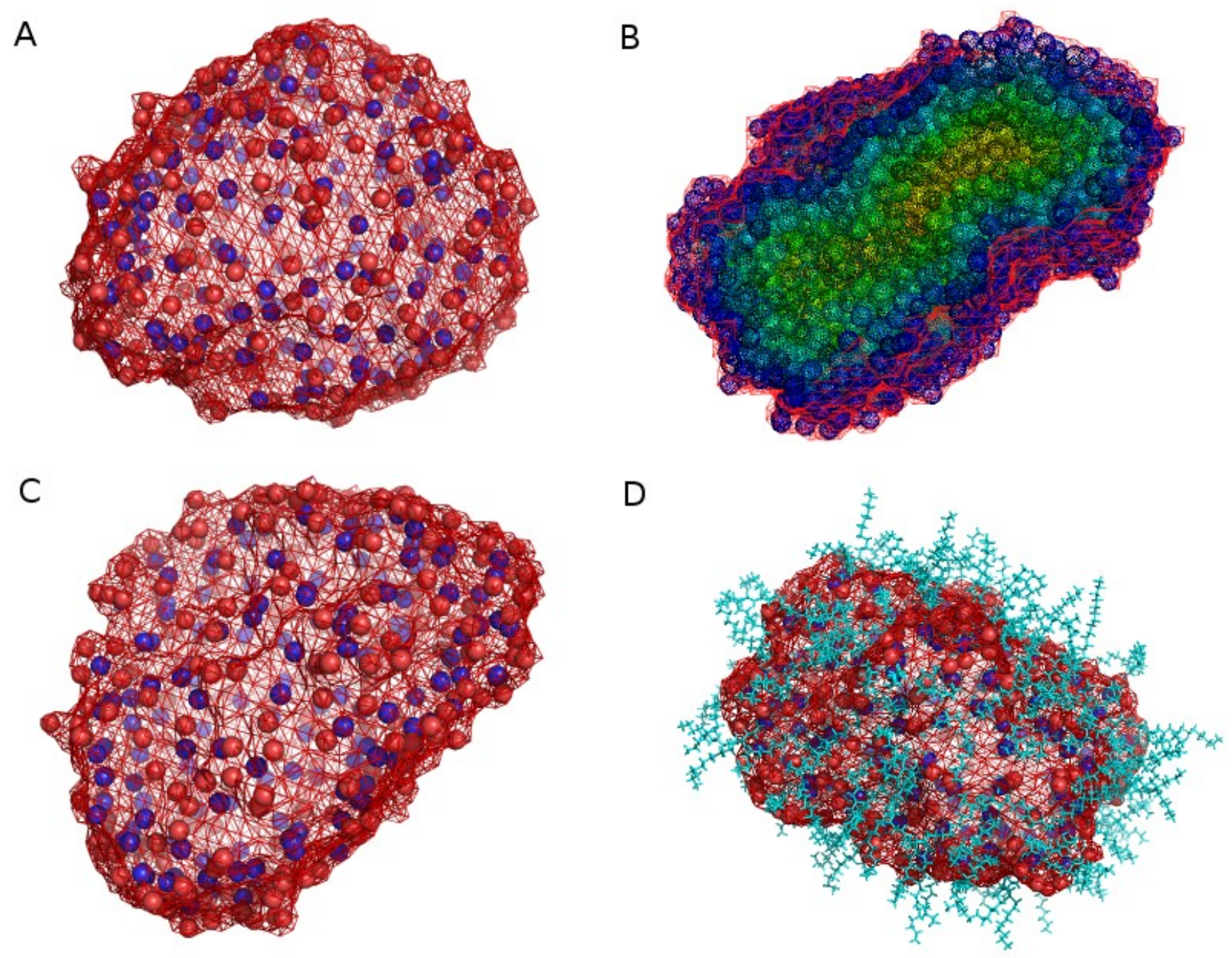

Figure S2. Structure of the polar core of micelle c150 after $6.5 \mathrm{~ns}$ (A), $7.0 \mathrm{~ns}$ (B), $7.5 \mathrm{~ns}$ (C) and $8.0 \mathrm{~ns}$ (D) of total simulation time. Boundary of the polar core (water, $\mathrm{Br}^{-}$, hexanol hydroxyl and CTAB trimethyl ammonium groups) is delineated by red wire-frame surface. In panels $\mathrm{A}, \mathrm{C}$ and $\mathrm{D}$, hexanol oxygen and CTAB nitrogen atoms are shown as red, blue spheres, respectively. In panel B, all polar core atoms are shown in space filling, colored by depth below boundary surface. In panel D, CTAB apolar tails are shown in cyan. 


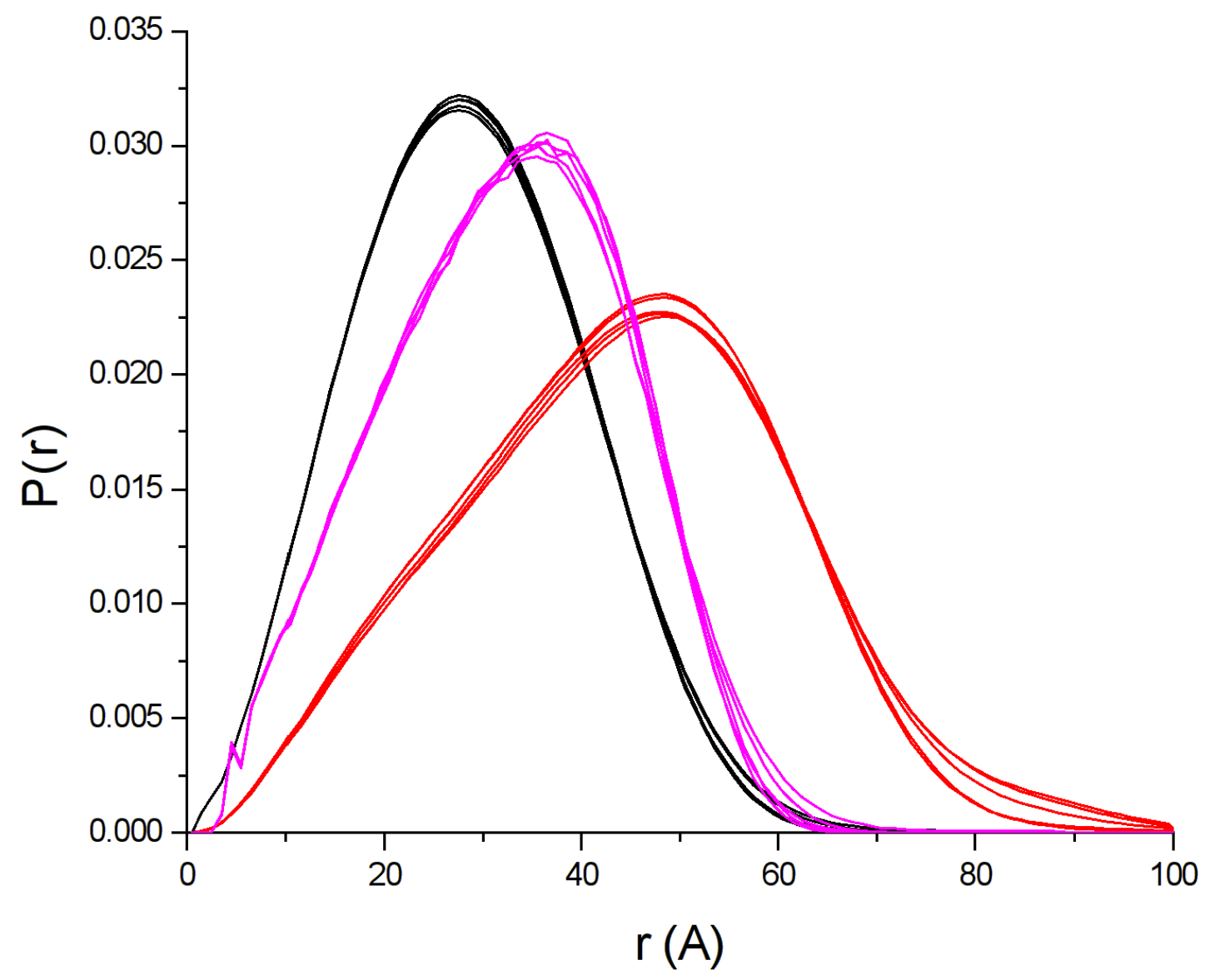

Figure S3. Shape distribution profiles for the c130 micelle for water (black), CTAB (red) and Br- ions (magenta) calculated from the initial $4 \mathrm{~ns}$ of sampling and subsequent four $2 \mathrm{~ns}$ batch samples 


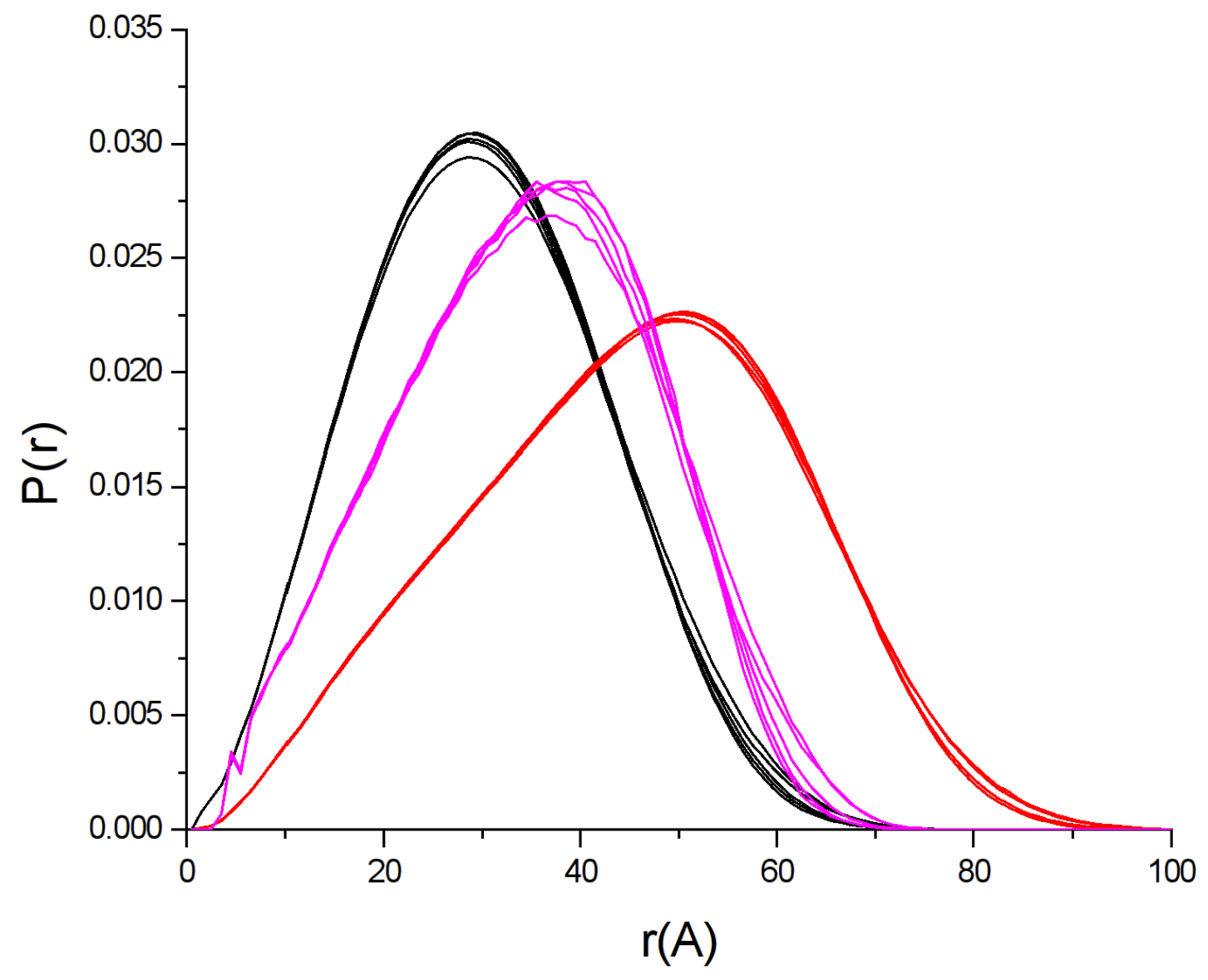

Figure S4. Shape distribution profiles for the $\mathrm{c} 150$ micelle for water (black), CTAB (red) and Br- ions (magenta) calculated from the initial $4 \mathrm{~ns}$ of sampling and subsequent four $2 \mathrm{~ns}$ batch samples. 


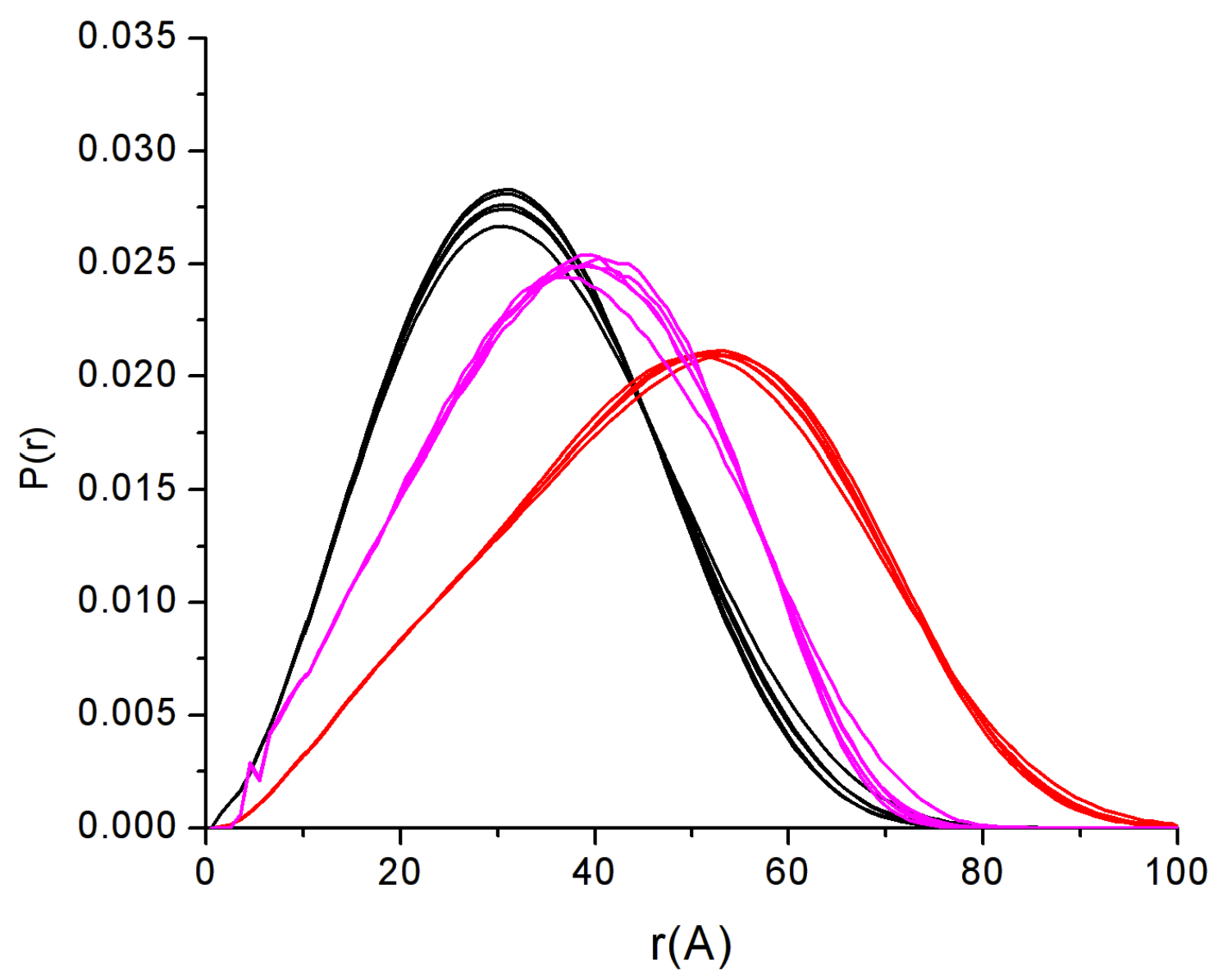

Figure S5. Shape distribution profiles for the c180 micelle for water (black), CTAB (red) and Br- ions (magenta) calculated from the initial $4 \mathrm{~ns}$ of sampling and subsequent four $2 \mathrm{~ns}$ batch samples 


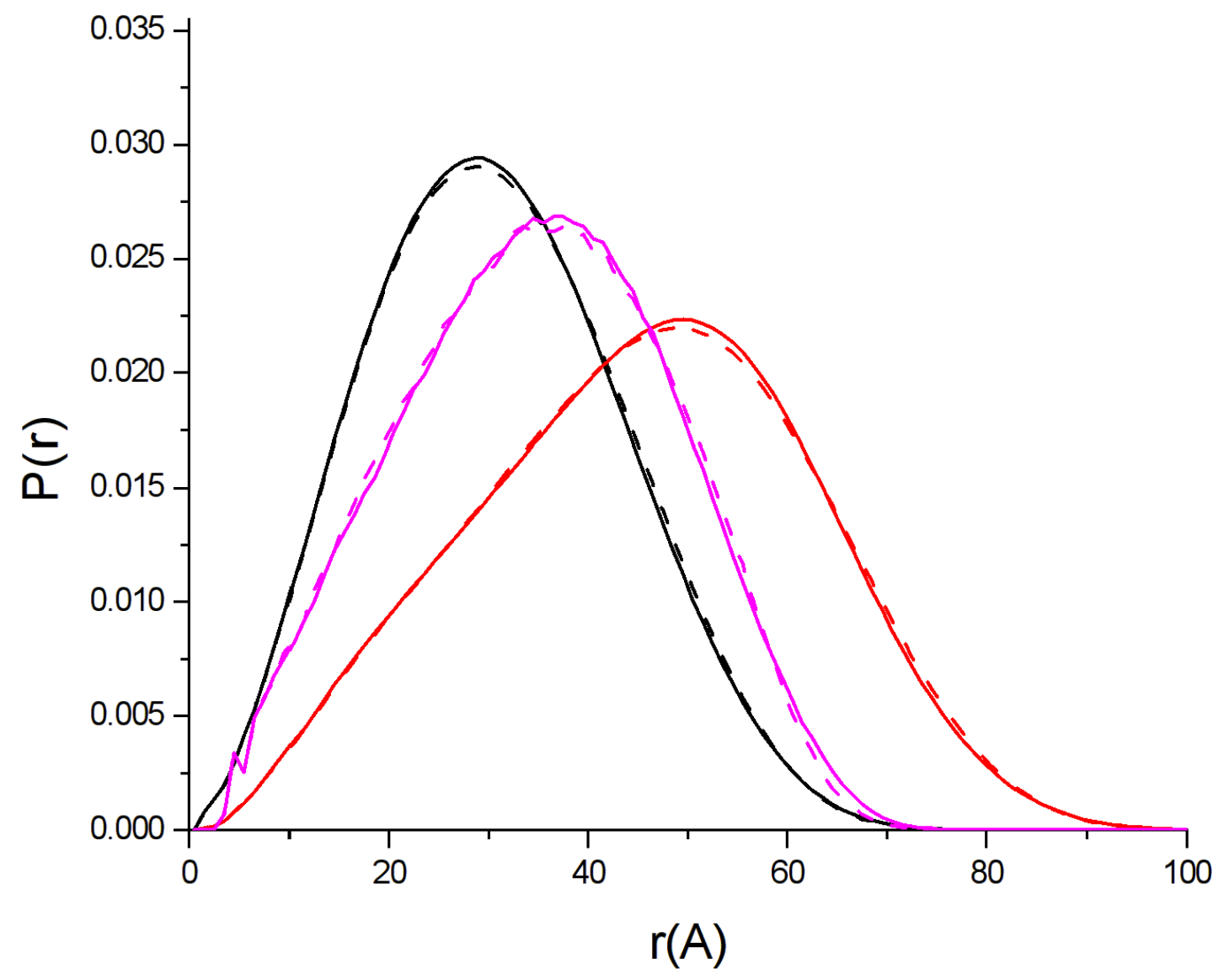

Figure S6. Shape distribution profiles for the $\mathrm{c} 150$ micelle for water (black), CTAB (red) and Br- ions (magenta) calculated using a minimum pentane solvent boundary layer of $7 \AA$ (solid) and $12 \AA$ (dashed) 


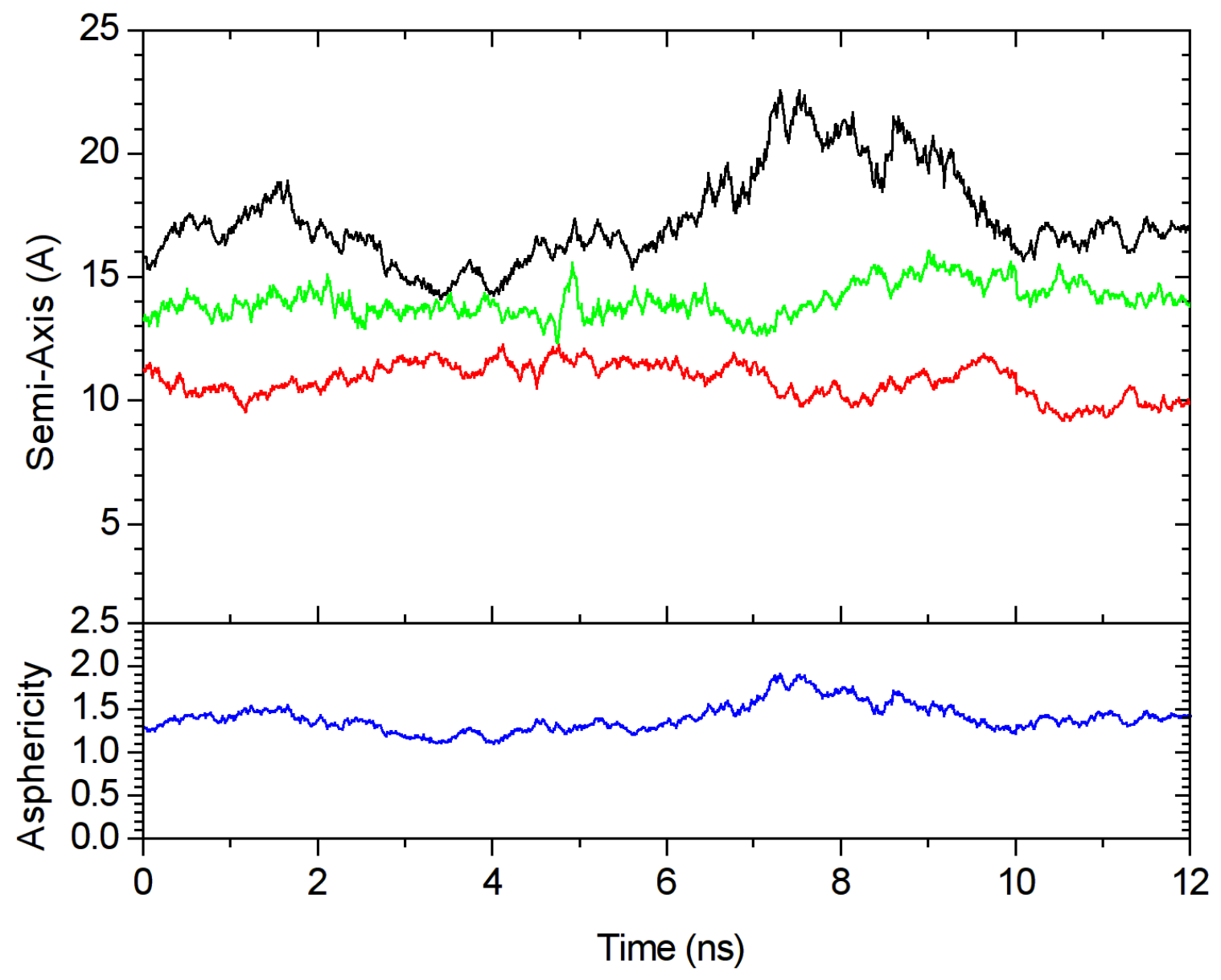

Figure S7. Upper panel: Time course of the semi-axes of the moment of inertia ellipsoid for the water component of the micelle containing $150 \mathrm{CTAB}$ molecules, 3000 water molecules. Long axis (black), short axis (red), and median axis (green). Lower panel: Time course of asphericity, defined as ratio of long axis to average of the other two (blue). 


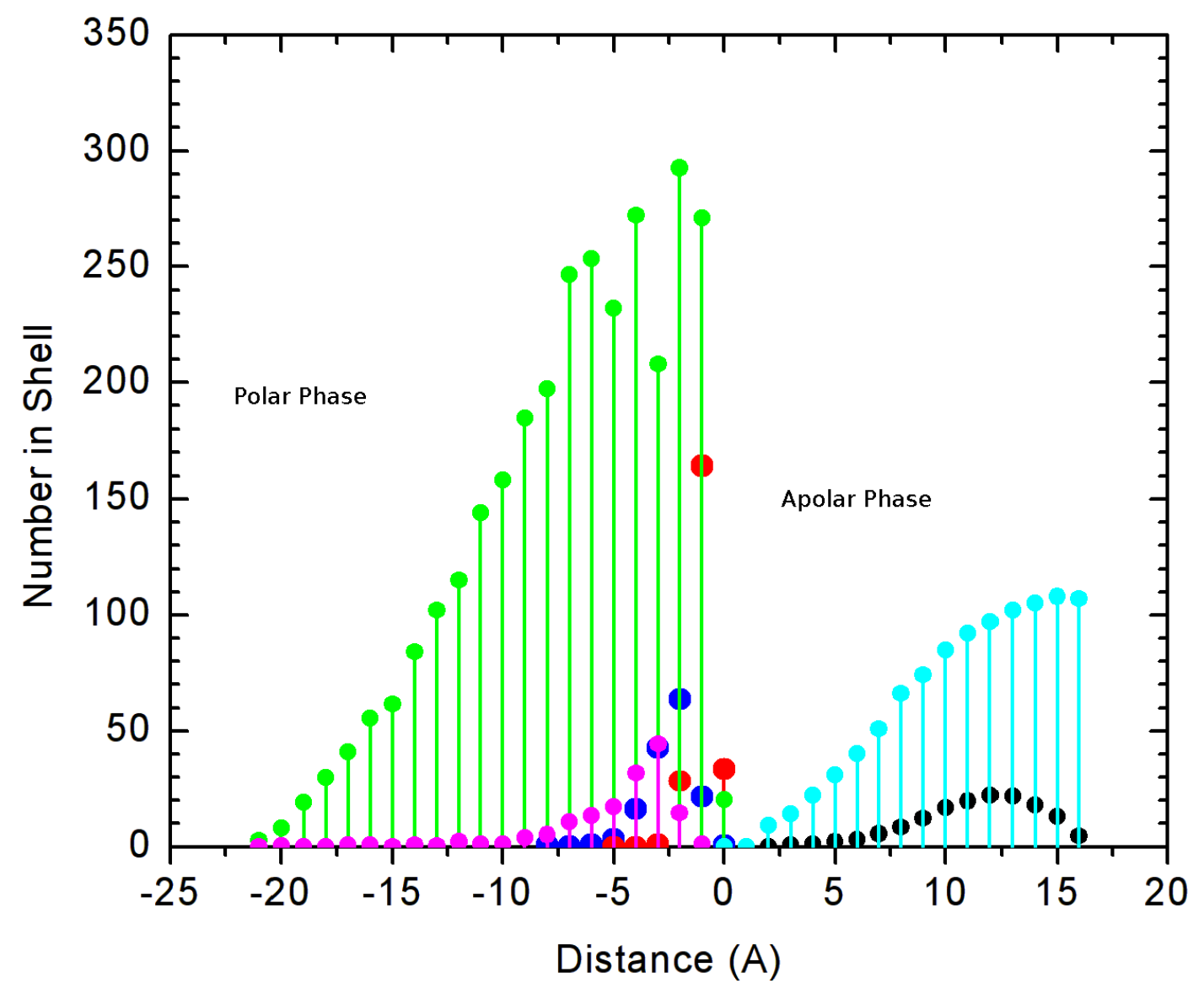

Figure S8. Average distribution of components in c150 micelle, expressed as the number of groups falling within each $1 \AA$ thick layer. Data were calculated from the initial $4 \mathrm{~ns}$ of sampling. Distance is relative to the surface of the polar phase: see methods section for definition. Negative, positive distances indicate position inside, outside this surface, respectively. Water (green), $\mathrm{Br}$ (purple), $\mathrm{OH}$ group of hexanol (red), $\mathrm{N}^{+}\left(\mathrm{CH}_{3}\right)_{3}$ group of $\mathrm{CTAB}$ (blue), $\mathrm{C}_{16}$ methyl group (tail) of CTAB (black), methyl group of pentane (cyan; distribution beyond $+17 \AA$ omitted.) 


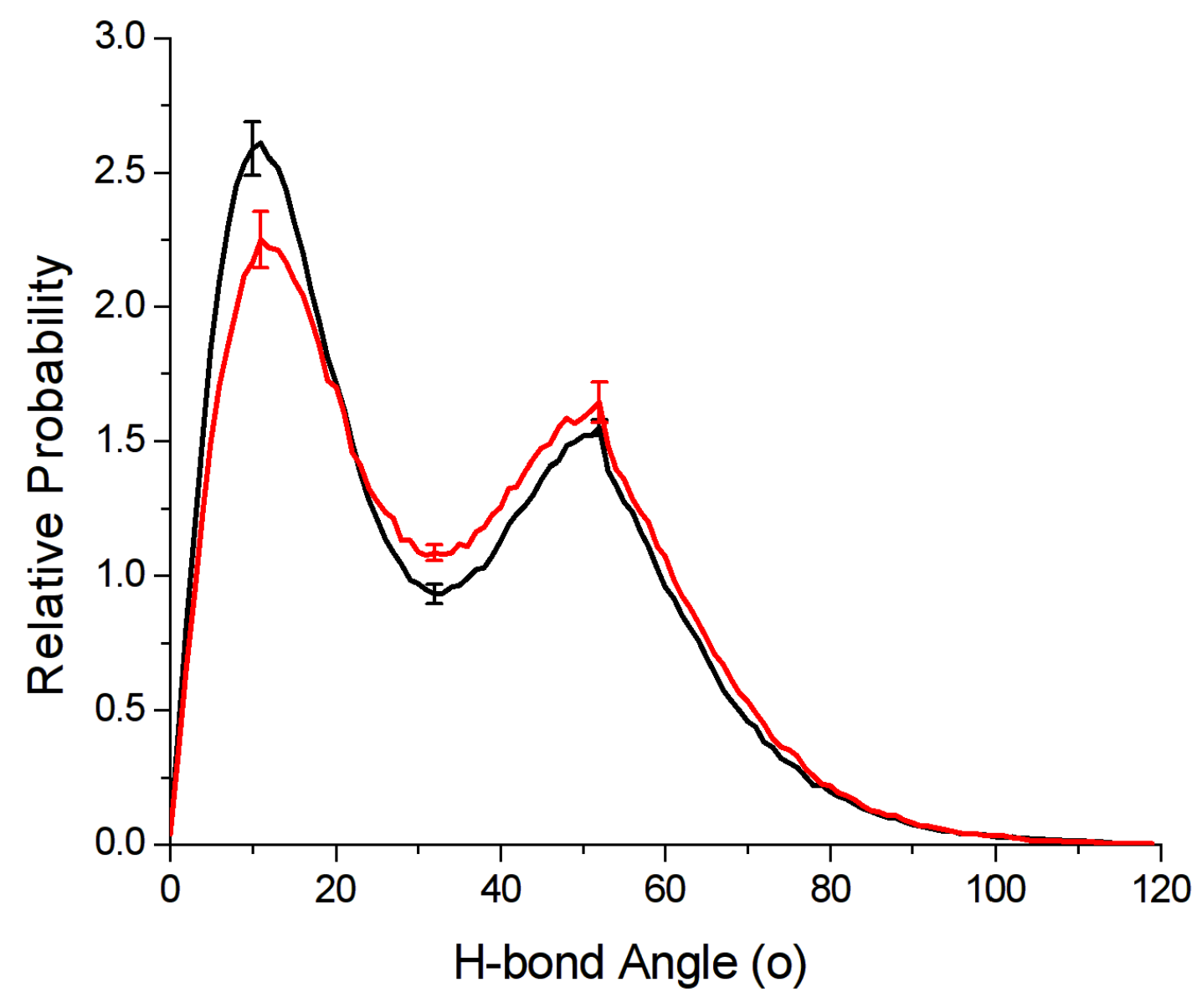

Figure S9 Water-water hydrogen bond angle distributions for aqueous phase of the c150 micelle averaged over $8 \mathrm{~ns}$. Outer-most $2 \AA$ layer is within $5 \AA$ of the CTAB head group (black). All other layers are statistically indistinguishable. Their average distribution is shown in red. 


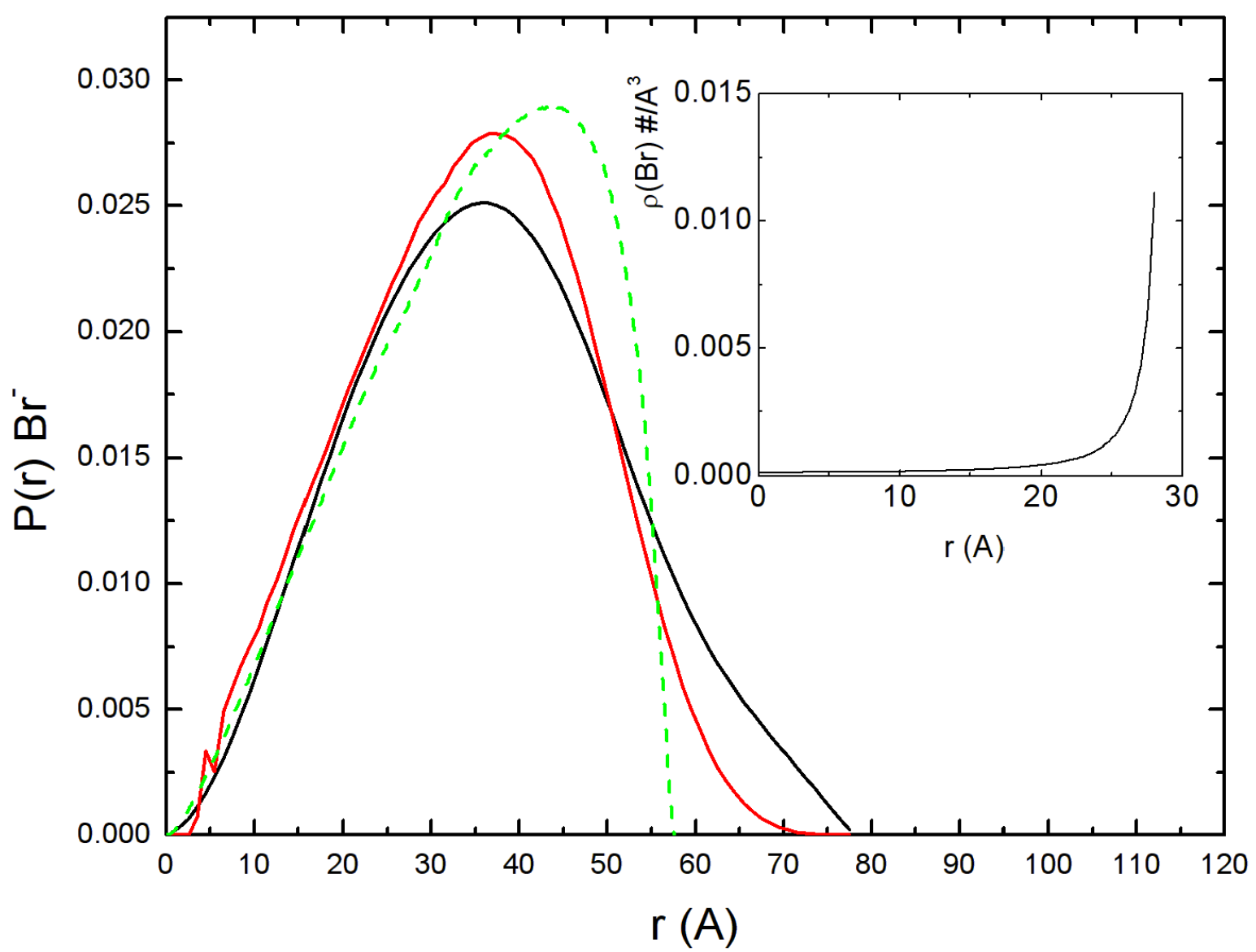

Figure S10. Shape distribution profiles obtained from SAXS (black), calculated from $\mathrm{Br}^{-}$ion distribution from MD simulation of micelles containing $150 \mathrm{CTAB}$ molecules (red), and from nonlinear Poisson-Boltzmann Eqn. using a sphere radius of $28 \AA$ and a water dielectric of 78.6 (green). Inset: Radial distribution of $\mathrm{Br}^{-}$density from the non-linear Poisson-Boltzmann Eqn. 